Original Article

\title{
POSTPARTUM HEALTH RELATED QUALITY OF LIFE AFTER DIFFERENT MODES OF DELIVERY AMONG WOMEN IN PAKISTAN: THE NEGLECTED LINK FOR BETTER MATERNAL and CHILD HEALTH
}

\author{
MADEEHA MALIK ${ }^{1}$, ZIRWA ASIM², AZHAR HUSSAIN ${ }^{3}$
}

\author{
${ }^{1,2}$ Hamdard Institute of Pharmaceutical Sciences, Hamdard University, Islamabad, Pakistan, ${ }^{3}$ Faculty of Pharmacy, Hamdard University, \\ Islamabad, Pakistan
}

Email: madeehamalik15@gmail.com

Received: 12 Jul 2017 Revised and Accepted: 06 Jun 2018

\begin{abstract}
Objective: The present study was designed to evaluate women postpartum quality of life after different modes of delivery in Pakistan.

Methods: A descriptive cross-sectional study design was used. A pre-validated tool SF-36 was self-administered to a sample of 382 women in the postpartum period (6-8 w, 10-12 w, 14-16 w,>9 mo,>15 mo) undergone through elective/emergency cesarean sections or normal vaginal delivery and had delivered a single live child. After data collection, data was cleaned coded and entered in SPSS version 21.0 . Descriptive statistics comprising of frequency and percentages was calculated. The non-parametric tests including Mann-Whitney and Kruskal-Walis ( $\mathrm{p} \geq 0.05$ ) were performed to find out the difference among different variables.
\end{abstract}

Results: Comparison of HRQOL domains by mode of delivery using Mann-Whitney test demonstrated a significant difference (p=0.01) between normal delivery and cesarean section. Women undergoing normal delivery had significantly higher scores as compared to women having cesarean section. Also, a significant difference ( $\mathrm{p}=0.027)$ among HRQOL scores was observed between working women and house wives and as well who had better socioeconomic status ( $\mathrm{p}=0.018)$.

Conclusion: The results of the present study concluded that postpartum quality of life of most of the women undergoing normal vaginal delivery was better as compared to women undergoing cesarean sections in twin cities of Pakistan. Surgical intervention during cesarean section might lead to consistent postpartum pain, inability to cope with needs of newborn and family which in turn can reduce postpartum quality of life among women.

Keywords: Cesarean sections, Health related quality of life, Normal vaginal delivery, Postpartum period, Women, Pakistan

(C) 2018 The Authors. Published by Innovare Academic Sciences Pvt Ltd. This is an open access article under the CC BY license (http://creativecommons.org/licenses/by/4.0/) DOI: http://dx.doi.org/10.22159/ijpps.2018v10i7.21284

\section{INTRODUCTION}

Cesarean sections have been increasing worldwide and have become a global concern. Cesarean sections should be reserved to treat or prevent fetal and maternal complications, but in reality, this has not been the actual practice [1]. Fear of labor pain and an increased tendency towards cesarean section has been causing a decline in normal vaginal delivery. According to World Health Organization, the reasonable rate of cesarean sections is $10-15 \%$. But this practice is rather above this limit in developing countries and the impact of this inappropriate rise in cesarean section has led to poor postpartum quality of life and depression among women. Doctors frequently had been persuading their patients to accept a scheduled cesarean section for conditions that either did not exist or did not justify the procedure. The reason behind this unethical practice might be money making or inadequate knowledge of gynecologists. Extensive research is required to identify different barriers in promoting maternal infant health, provide information for evidence based practice and to assist women in informed decision making. An association of obesity with cesarean section rate has been reported and women with $\mathrm{BMI}>30 \mathrm{~kg} / \mathrm{m} 2$ at $16 \mathrm{w}$ of pregnancy had a high prevalence of cesarean section rate in particular primigravidae women. The risk of instrumental delivery, induced labor and thereby increased cesarean section rate was also reported in obese pregnant women [2].

The postpartum period is a critical time for a woman, her newborn and her family, on a physiological, emotional and social level. Postpartum problems like poor physical and mental health lead to poor postpartum quality of life in women, which has a devastating effect on the health related quality of life of mother, newborn and her family $[3,4]$. Cesarean section has been increasing at an alarming rate and causing serious deleterious effects on the infant and maternal postpartum quality of life in Pakistan. A study conducted in Lahore reported $21.07 \%$ cesarean section rate, of which $11.33 \%$ were elective and $88.67 \%$ were emergency cesarean sections. Complications during pregnancy and no antenatal care were the main causes of maternal morbidity and mortality. Other causes of cesarean sections were dystocia, fetal distress and previous cesarean sections $[5,6]$. Assessment of postpartum quality of life after different modes of delivery is an unexplored area of research, particularly in Pakistan. To date, there is not even a single study up to our best of knowledge which has explored maternal quality of life during postpartum period in Pakistan. Thus, comprehensive research on assessment of women postpartum quality of life after different modes of deliveries is much required to promote maternal and infant health. Therefore, present study was designed to evaluate women postpartum quality of life after different modes of delivery in Pakistan.

\section{MATERIALS AND METHODS}

A descriptive cross-sectional study design was used to assess the physical functioning, role limitation due to physical problems or role physical, bodily pain, general health, vitality, social functioning, role limitation due to emotional problems or role emotional and emotional well-being among women (fig. 1). National bioethical committee is present for this type of research and it states that only institutional head approval is required for this type of study [7]. Moreover in Pakistan, questionnaire-based studies do not need any endorsement from Ministry of Health. Despite that, prior information was sent to the Ministry of Health, Government of Pakistan for the execution of this research. For data collection approval from MS of the hospitals was taken. Informed 
and verbal consent for participation was also taken from the respondents. Respondents were ensured for the confidentiality of information verbally as well as confidentiality under taking was signed by the principal investigator. Study site for this research included all immunization centers in public and private healthcare facilities in twin cities of Pakistan. Study respondents included women in the postpartum period $(6-8 \mathrm{w}, 10-12 \mathrm{w}, 14-16 \mathrm{w},>9$ mo,>15 mo). Inclusion criteria were women aged $16-50$ y by the time of delivery; women who had elective or emergency cesarean sections and normal vaginal delivery; women in the postpartum period and women who had delivered a single live child. Exclusion criteria included a history of psychosis, bipolar disorder, schizophrenia, current psychotic illness, a previous baby with a congenital abnormality; a previous perinatal death; age less than 16 y; a history suggesting severe personality dysfunction; multiple gestations; and obstetric or neonatal complications.

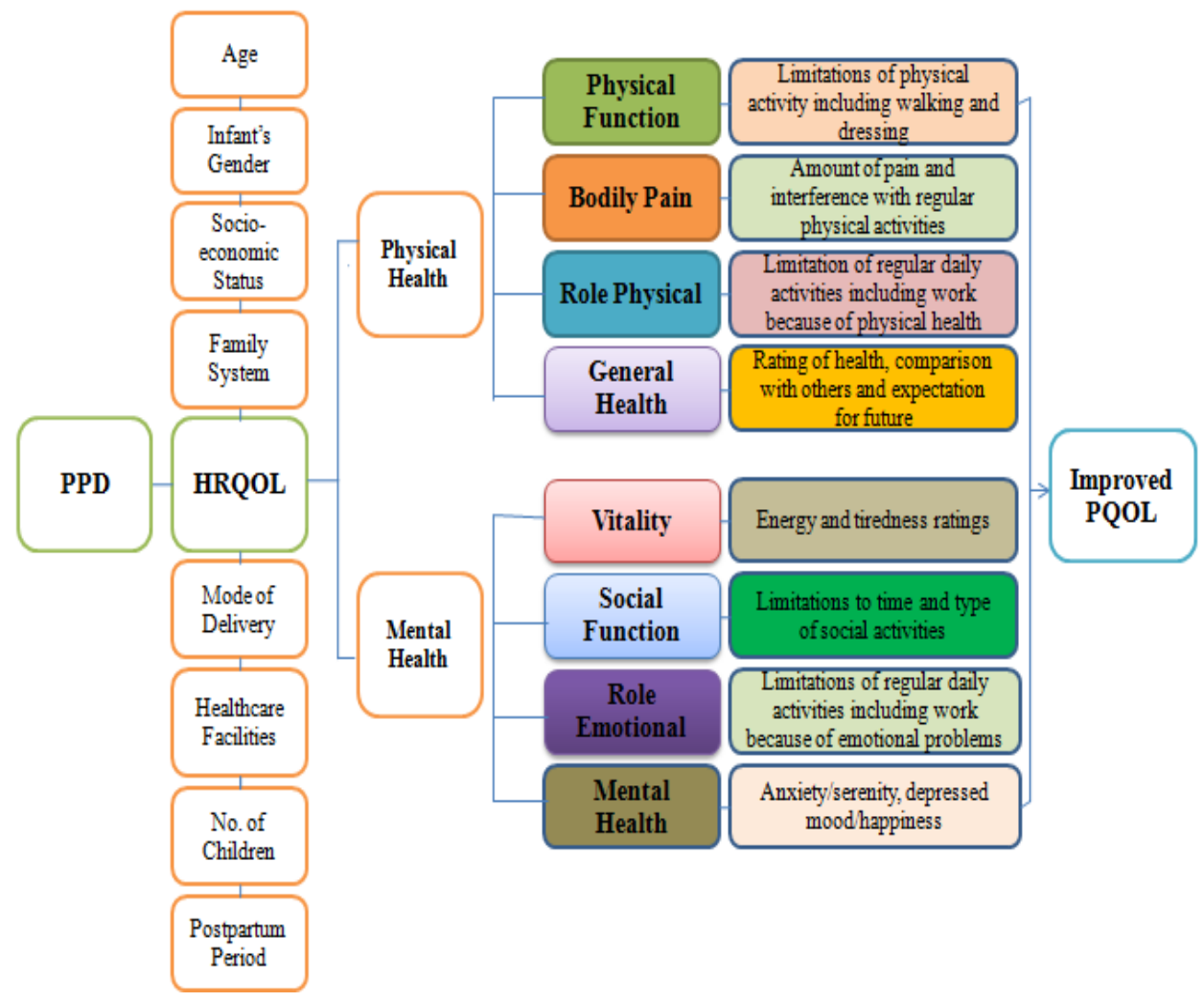

Fig. 1: Conceptual framework

\section{Sample size and sampling procedures}

Calculation of sample size was performed by Rao soft sample size calculator to determine the size of sample representing postpartum women. The sample size was calculated as 382 to achieve $95 \%$ confidence interval at $5 \%$ margin of error. As there was no updated record of postpartum women in the healthcare facilities, convenience sampling technique was used for this study. According to convenience sampling, all the respondents that were available at the time of data collection were selected. Prospective data was collected directly from the respondents at the respective healthcare facility where they were treated.

\section{Data collection tool}

Data collection tool used in this study was Short form health survey (SF-36). Written permission had been obtained from Optum for using SF-36. The tool was slightly modified according to study objectives and socio-demographics of the country. The scale comprises of 36 items in total which are divided in eight subscales: perceived mental health (5 items), physical functioning (10 items), general health perceptions (5items), role limitations due to physical problems (4 items), role limitation due to emotional problems (3 items), social functioning ( 2 items), vitality ( 4 items) and bodily pain ( 2 items). The physical function (PF) subscale reflected the degree to which physical activities are limited by disease, such as climbing stairs, self-care, walking, carrying weights, moderate to intense efforts and bending. Role limitations due to physical problems assesses to the degree to which physical health limits work and other daily activities. Role limitations due to emotional problems assesses to the degree to which emotional health limits work and other daily activities. Bodily pain evaluates the effect and intensity of pain in the daily work and activities of patients. Vitality reflects the feeling of energy as compared to exhaustion and fatigue in patients. Perceived mental health evaluates different aspects of mental health as perceived by patients such as anxiety, depression, emotional control and behavioural control. Social Functioning evaluates the impact that disease has on social functioning of patients due to emotional or physical health. General health perception reflects the assessment of current health and future aspects of resistance to illness and health as perceived by patients themselves.

Sf-36 administration involved a number of steps. Firstly the respondent was greeted and assessed. If during assessment respondent was found unable to understand English, other approved language version was determined or interviewer administration was used. A large-font form or interviewer administration was used if visual problems were present. Then survey was introduced and survey form was given. The respondent was given instructions on how to fill the form and they were answered if they had any issue in filling the form. The form was collected back and checked for completeness before the respondent left. Respondent was thanked for filling the form.

\section{Scoring of the tool}

Several steps were included in this process, including changing outof range values to missing, recoding values for 10 items, and substituting person-specific estimates for missing items. After recoding, the raw scale scores for each health domain were 
determined. The total raw score was simple algebraic sum of final response values of all items in a given scale. In the next step Health domain scale total raw scores were transformed to 0-100 scores using the following formula; ((Actual raw score-Lowest possible raw score)/Possible raw score range) x 100. Health domain scale 0-100 scores were transformed to $T$ scores using health domain $z$ scores.

\section{Reliability and validity of the tool}

SF-36 is a pre-validated tool but still two focus group discussions had been conducted at different time intervals with experts from hospitals, academia, regulatory and pharmaceutical industries for face and content validation of the tool. Beside this pilot testing had been conducted at $10 \%$ of the sample size to test the reliability of the tool after data collection. The value of Cronbach's alpha was 0.93 for SF-36, which was satisfactory considering that 0.68 is the cutoff value being disapproved.

\section{Data collection and analysis}

Data was collected by the principal investigator. The respondents were identified and after obtaining written/verbal consent from them, the questionnaire was hand delivered to them. The questionnaire was collected back on the same day to avoid study biasness. After data collection, data was cleaned coded and entered in SPSS version 21.0. Skewness test was performed and histograms with normal curves were used to check the normal distribution of data. Descriptive statistics comprising of frequency and percentages was calculated. The non-parametric tests including Mann-Whitney and Kruskal-Walis ( $\mathrm{p} \geq 0.05$ ) were performed to find out the difference among different variables.

\section{RESULTS}

\section{Demographic characteristics}

Out of 382 respondents, $42.9 \%(n=162)$ belonged to Islamabad while $57.6 \%(n=220)$ were from Rawalpindi. Regarding the mode of delivery, $46.1 \%(n=176)$ women had cesarean section while $53.9 \%$ $(\mathrm{n}=156)$ women had normal vaginal delivery. Of the total respondents, $23.3 \%(\mathrm{n}=89)$ women were belonging to postpartum period $6-8 \mathrm{w}$, $15.2 \%(n=58)$ were from $10-12 \mathrm{w}$ postpartum period, $27.2 \%(\mathrm{n}=104)$ women were from 14-16 w postpartum period, $22.8 \%(\mathrm{n}=87)$ women were from 9 mo postpartum period and 11.5\% (n=44) women were from 15 mo postpartum period (table 1 ).

Table 1: Demographic characteristic of respondents

\begin{tabular}{|c|c|c|}
\hline \multirow{2}{*}{$\begin{array}{l}\text { Indicator } \\
\text { Age }\end{array}$} & \multicolumn{2}{|c|}{ n (\%) } \\
\hline & $16-20 \mathrm{Y}$ & $26(6.8)$ \\
\hline & $21-25 Y$ & $138(36.1)$ \\
\hline & $26-30 \mathrm{Y}$ & $146(38.2)$ \\
\hline & $31-35 Y$ & $60(15.7)$ \\
\hline & $36-40 \mathrm{Y}$ & $12(3.2)$ \\
\hline & $41-45 Y$ & 0 \\
\hline & $46-50 \mathrm{Y}$ & 0 \\
\hline \multirow[t]{2}{*}{ City } & Islamabad & $162(42.9)$ \\
\hline & Rawalpindi & $220(57.1)$ \\
\hline \multirow[t]{5}{*}{ Postpartum period } & $6-8 w$ & $89(23.3)$ \\
\hline & $10-12 \mathrm{w}$ & $58(15.2)$ \\
\hline & $14-16 \mathrm{w}$ & $104(27.2)$ \\
\hline & $9 \mathrm{mo}$ & $87(22.8)$ \\
\hline & $15 \mathrm{mo}$ & $44(11.5)$ \\
\hline \multirow[t]{2}{*}{ Mode of delivery } & Cesarean sections & $176(46.1)$ \\
\hline & Normal Delivery & $206(53.9)$ \\
\hline \multirow{2}{*}{ Infant's gender } & Male & $193(50.5)$ \\
\hline & Female & $189(49.5)$ \\
\hline \multirow[t]{2}{*}{ Healthcare facility } & Public & $207(54.2)$ \\
\hline & Private & $175(45.8)$ \\
\hline \multirow[t]{2}{*}{ Respondent profession } & House wife & $356(93.2)$ \\
\hline & Working women & $26(6.8)$ \\
\hline \multirow[t]{2}{*}{ Family system } & Separate & $114(29.8)$ \\
\hline & Combined & $268(70.2)$ \\
\hline \multirow[t]{7}{*}{ Husband age } & $16-20 \mathrm{Y}$ & $4(1.0)$ \\
\hline & $21-25 Y$ & $46(12.0)$ \\
\hline & $26-30 \mathrm{Y}$ & $138(36.1)$ \\
\hline & $31-35 Y$ & $115(30.1)$ \\
\hline & $36-40 \mathrm{Y}$ & $60(15.7)$ \\
\hline & $41-45 Y$ & $16(4.2)$ \\
\hline & $46-50 \mathrm{Y}$ & $3(0.9)$ \\
\hline \multirow[t]{7}{*}{ Respondent's qualification } & Illiterate & $53(13.9)$ \\
\hline & Primary & $32(8.4)$ \\
\hline & Secondary & $30(7.9)$ \\
\hline & Matriculation & $91(23.8)$ \\
\hline & Intermediate & $65(17.0)$ \\
\hline & Bachelors & $70(18.3)$ \\
\hline & Higher & $41(10.7)$ \\
\hline \multirow[t]{7}{*}{ Husband's qualification } & Illiterate & $35(9.2)$ \\
\hline & Primary & $26(6.8)$ \\
\hline & Secondary & $25(6.6)$ \\
\hline & Matriculation & $128(33.5)$ \\
\hline & Intermediate & $62(16.2)$ \\
\hline & Bachelors & $62(16.2)$ \\
\hline & Higher & $44(11.5)$ \\
\hline Monthly income & No income & $15(3.9)$ \\
\hline \multirow{2}{*}{ (Rupees) } & 10,000 or less & $101(26.4)$ \\
\hline & $11,000-20,000$ & $111(29.1)$ \\
\hline
\end{tabular}




\begin{tabular}{|c|c|c|}
\hline & $21,000-30,000$ & $63(16.5)$ \\
\hline & $31,000-40,000$ & $33(8.6)$ \\
\hline & $41,000-50,000$ & $17(4.5)$ \\
\hline & Greater than 50,000 & $42(11.0)$ \\
\hline \multirow[t]{3}{*}{ Number of children } & One child & $135(35.3)$ \\
\hline & Two-five child & $243(63.7)$ \\
\hline & Greater than five child & $4(1.0)$ \\
\hline \multirow[t]{8}{*}{ Husband's profession } & Professional & $38(9.9)$ \\
\hline & Government Job & $43(11.3)$ \\
\hline & Businessman & $28(7.3)$ \\
\hline & Shopkeeper & $100(26.2)$ \\
\hline & Abroad & $24(6.3)$ \\
\hline & Daily wager & $78(20.4)$ \\
\hline & Jobless & $12(3.1)$ \\
\hline & Private job in company & $59(15.5)$ \\
\hline \multirow[t]{4}{*}{ How many days you lived in hospital after delivery? } & None & $156(40.7)$ \\
\hline & One to two days & $85(22.3)$ \\
\hline & Three to five days & $132(34.6)$ \\
\hline & Greater than five days & $9(2.4)$ \\
\hline \multirow[t]{3}{*}{ Number of hospital visits after delivery? } & None & $200(52.4)$ \\
\hline & One to two visits & $175(45.8)$ \\
\hline & Three to five visits & $7(1.8)$ \\
\hline \multirow[t]{5}{*}{ Total cost on delivery } & Free & $106(27.7)$ \\
\hline & $1000-20,000$ & $180(47.1)$ \\
\hline & $21,000-50,000$ & $67(17.5)$ \\
\hline & $51,000-1 \mathrm{Lac}$ & $27(7.1)$ \\
\hline & Greater than 1 Lac & $2(0.6)$ \\
\hline
\end{tabular}

$\%$-Percentage; $\mathrm{n}=382$

\section{Impact of mode of delivery on HRQOL}

The results highlighted that women undergoing normal vaginal delivery (NVD) had overall better postpartum quality of life as compared to women having cesarean sections (CS) in all domains of health related quality of life. In NVD, physical functioning was the best health domain with mean scores $(78.57, \pm 25.08)$ and bodily pain was the worst health domain $(51.08, \pm 24.49)$. On the other hand, physical functioning was the better health domain in cesarean sections with mean scores $(65.63, \pm 27.11)$ and bodily pain was worst $(39.84, \pm 24.47)$. A detailed description is given (table 2).

Table 2: Impact of mode of delivery on HRQOL

\begin{tabular}{lll}
\hline Indicator & Normal vaginal delivery & Cesarean section \\
\cline { 2 - 3 } & Mean (SD) & $65.63 \pm 27.11$ \\
\hline Physical functioning & $78.57 \pm 25.08$ & $42.01 \pm 27.06$ \\
Role physical & $52.76 \pm 25.45$ & $39.84 \pm 24.47$ \\
Bodily pain & $51.08 \pm 24.49$ & $47.86 \pm 28.77$ \\
General health & $51.37 \pm 26.05$ & $61.58 \pm 22.72$ \\
Social functioning & $67.29 \pm 20.67$ & $49.20 \pm 29.34$ \\
Role emotional & $53.07 \pm 27.77$ & $51.21 \pm 18.04$ \\
Vitality & $52.55 \pm 17.25$ & $60.57 \pm 20.21$ \\
Mental health & $62.60 \pm 17.95$ & \\
\hline
\end{tabular}

Data are represented as mean $\pm \mathrm{SD}$

\section{Comparison of domains of HRQOL by demographic characteristics}

Comparison of HRQOL domains by mode of delivery using MannWhitney test demonstrated a significant difference $(p=0.01)$ between normal delivery and cesarean section. Women undergoing normal delivery had significantly higher scores as compared to women having cesarean section. Also, a significant difference $(p=0.027)$ among HRQOL scores was observed between working women and house wives. Analyzing the scores of the respondents with monthly income using Kruskal-Walis test reported a significantly higher HRQOL $(\mathrm{p}=0.018)$ of women having 41,000-50,000 income. A detailed description is given (table 3).

Table 3: Comparison of domains of HRQoL by demographic characteristics

\begin{tabular}{|c|c|c|c|c|c|c|c|c|c|c|c|c|}
\hline \multirow[t]{2}{*}{ Indicator } & \multicolumn{4}{|c|}{ Physical health } & \multicolumn{4}{|c|}{ Mental health } & \multicolumn{4}{|c|}{ Composite } \\
\hline & $\mathbf{n}$ & $\begin{array}{l}\text { Mean } \\
\text { rank }\end{array}$ & Test stat & $\begin{array}{l}\text { p- } \\
\text { value }\end{array}$ & $\mathbf{n}$ & $\begin{array}{l}\text { Mean } \\
\text { rank }\end{array}$ & Test stat & $\begin{array}{l}\text { p- } \\
\text { value }\end{array}$ & $\mathbf{n}$ & $\begin{array}{l}\text { Mean } \\
\text { rank }\end{array}$ & Test stat & $\begin{array}{l}\text { p- } \\
\text { value }\end{array}$ \\
\hline \multicolumn{13}{|c|}{ Gender of baby } \\
\hline Male & 193 & 194.80 & 17602.500 & $0.285^{\mathrm{a}}$ & 192 & 196.81 & 16837.000 & $0.125^{\mathrm{a}}$ & 192 & 195.64 & 17060.500 & $0.177^{\mathrm{a}}$ \\
\hline female & 189 & 188.13 & & & 188 & 184.06 & & & 188 & 185.25 & & \\
\hline \multicolumn{13}{|c|}{ Age of the respondent } \\
\hline $16-20$ & 26 & 189.08 & 1.406 & $0.843^{\mathrm{b}}$ & & 185.75 & 5.895 & $0.207^{b}$ & 26 & 185.10 & 3.431 & $0.488^{b}$ \\
\hline $21-25$ & 138 & 198.23 & & & & 200.88 & & & 138 & 199.54 & & \\
\hline $26-30$ & 146 & 190.96 & & & & 194.88 & & & 144 & 192.49 & & \\
\hline
\end{tabular}




\begin{tabular}{|c|c|c|c|c|c|c|c|c|c|c|c|c|}
\hline $31-35$ & 60 & 178.16 & & & & 162.22 & & & 60 & 168.89 & & \\
\hline $36-40$ & 12 & 192.58 & & & & 170.29 & & & 12 & 182.42 & & \\
\hline \multicolumn{13}{|c|}{ Postpartum period } \\
\hline $6-8 w$ & 89 & 182.31 & 4.208 & $0.379^{b}$ & 89 & 179.10 & 4.750 & $0.314^{\mathrm{b}}$ & 89 & 178.26 & 4.822 & $0.306^{b}$ \\
\hline $10-12 \mathrm{w}$ & 58 & 182.81 & & & 57 & 186.03 & & & 57 & 185.80 & & \\
\hline $14-16 \mathrm{w}$ & 104 & 192.54 & & & 104 & 184.27 & & & 104 & 188.05 & & \\
\hline $9 \mathrm{mo}$ & 87 & 190.35 & & & 86 & 198.31 & & & 86 & 193.38 & & \\
\hline $15 \mathrm{mo}$ & 44 & 221.34 & & & 44 & 218.83 & & & 44 & 221.49 & & \\
\hline \multicolumn{13}{|c|}{ Healthcare facility } \\
\hline Public & 207 & 1822.22 & 16192.000 & $0.38^{\mathrm{a}}$ & 206 & 181.60 & 16089.000 & $0.43^{\mathrm{a}}$ & 206 & 180.67 & 15897.500 & $0.29^{a}$ \\
\hline private & 175 & 202.47 & & & 174 & 201.03 & & & 174 & 202.14 & & \\
\hline \multicolumn{13}{|c|}{ Family system } \\
\hline Combined & 268 & 196.79 & 13859.500 & $0.73^{\mathrm{a}}$ & 268 & 193.77 & 14132.500 & $0.187^{a}$ & 268 & 194.49 & 13938.000 & $0.132^{\mathrm{a}}$ \\
\hline separate & 114 & 179.07 & & & 112 & 182.68 & & & 112 & 180.95 & & \\
\hline \multicolumn{13}{|c|}{ Number of children } \\
\hline 1 child & 135 & 205.52 & 3.877 & $0.144^{\mathrm{b}}$ & 134 & 202.75 & 4.682 & $0.096^{b}$ & 134 & 204.82 & 4.671 & $0.097^{b}$ \\
\hline 2-5 children & 243 & 183.19 & & & 242 & 182.52 & & & 242 & 181.73 & & \\
\hline$>5$ children & 4 & 223.00 & & & 4 & 262.88 & & & 4 & 241.12 & & \\
\hline \multicolumn{13}{|c|}{ Husband's profession } \\
\hline Professionals & 38 & 218.25 & 8.433 & $0.296^{\mathrm{b}}$ & 37 & 207.30 & 6.993 & $0.430^{\mathrm{b}}$ & 37 & 216.73 & 8.942 & $0.257^{b}$ \\
\hline Govt job & 43 & 196.34 & & & 43 & 207.83 & & & 43 & 202.09 & & \\
\hline Businessman & 28 & 215.39 & & & 28 & 206.04 & & & 28 & 213.96 & & \\
\hline Shopkeeper & 100 & 192.76 & & & 100 & 188.38 & & & 100 & 188.33 & & \\
\hline Abroad & 24 & 210.56 & & & 24 & 213.06 & & & 24 & 210.27 & & \\
\hline Daily wagers & 78 & 167.65 & & & 78 & 168.33 & & & 78 & 165.53 & & \\
\hline Jobless & 12 & 181.46 & & & 11 & 176.18 & & & 11 & 185.41 & & \\
\hline Private job & 59 & 183.08 & & & 59 & 186.36 & & & 59 & 184.07 & & \\
\hline \multicolumn{13}{|c|}{ Profession of respondent } \\
\hline $\begin{array}{l}\text { Working } \\
\text { women }\end{array}$ & 26 & 222.94 & 3810.500 & $0.067^{a}$ & 25 & 225.90 & 3552.500 & $0.053^{a}$ & 25 & 231.48 & 3413.500 & $0.027^{a^{*}}$ \\
\hline \multicolumn{13}{|c|}{ Husband's age } \\
\hline $16-20$ & 4 & 215.38 & 5.369 & $0.497^{b}$ & 4 & 193.50 & 5.197 & $0.519^{b}$ & 4 & 205.50 & 6.149 & $0.407^{\mathrm{b}}$ \\
\hline $21-25$ & 46 & 186.00 & & & 46 & 182.57 & & & 46 & 181.95 & & \\
\hline $26-30$ & 138 & 198.42 & & & 138 & 201.99 & & & 138 & 199.99 & & \\
\hline $31-35$ & 115 & 183.53 & & & 113 & 178.76 & & & 113 & 181.00 & & \\
\hline $36-40$ & 60 & 193.31 & & & 60 & 188.39 & & & 60 & 190.42 & & \\
\hline $41-45$ & 16 & 213.72 & & & 16 & 217.22 & & & 16 & 217.34 & & \\
\hline $46-50$ & 3 & 76.33 & & & 3 & 121.50 & & & 3 & 81.33 & & \\
\hline \multicolumn{13}{|c|}{ Age of the respondent } \\
\hline $16-20$ & 26 & 189.08 & 1.406 & $0.843^{\mathrm{b}}$ & 26 & 185.75 & 5.895 & $0.207^{b}$ & 26 & 185.10 & 3.431 & $0.488^{b}$ \\
\hline $21-25$ & 138 & 198.23 & & & 138 & 200.88 & & & 138 & 199.54 & & \\
\hline $26-30$ & 146 & 190.96 & & & 144 & 194.88 & & & 144 & 192.49 & & \\
\hline $31-35$ & 60 & 178.16 & & & 60 & 162.22 & & & 60 & 168.89 & & \\
\hline $36-40$ & 12 & 192.58 & & & 12 & 170.29 & & & 12 & 182.42 & & \\
\hline Monthly incor & & & & & & & & & & & & \\
\hline No income & 15 & 159.37 & 13.783 & $0.032^{b^{*}}$ & 14 & 152.86 & 12.800 & $0.046^{\mathrm{b}^{*}}$ & 14 & 157.89 & 15.272 & $0.018^{\mathrm{b}^{*}}$ \\
\hline 10,000 or less & 101 & 173.49 & & & 101 & 176.78 & & & 101 & 172.39 & & \\
\hline $11000-20000$ & 111 & 179.10 & & & 111 & 175.58 & & & 111 & 175.49 & & \\
\hline $21000-30000$ & 63 & 205.28 & & & 63 & 217.47 & & & 63 & 210.94 & & \\
\hline $31000-40000$ & 33 & 212.58 & & & 33 & 199.76 & & & 33 & 208.24 & & \\
\hline $41000-50000$ & 17 & 231.21 & & & 17 & 217.18 & & & 17 & 225.88 & & \\
\hline$>50,0000$ & 42 & 225.76 & & & 41 & 217.60 & & & 41 & 226.54 & & \\
\hline Qualification & the & spondent & & & & & & & & & & \\
\hline Illiterate & 53 & 167.61 & 19.333 & $0.004^{b^{*}}$ & 53 & 167.37 & 15.230 & $0.019 \mathrm{~b}^{*}$ & 53 & 164.94 & 20.048 & $0.003^{\mathrm{b}^{*}}$ \\
\hline Primary & 32 & 190.75 & & & 32 & 182.34 & & & 32 & 186.09 & & \\
\hline Secondary & 30 & 146.85 & & & 30 & 163.95 & & & 30 & 148.57 & & \\
\hline Matriculation & 91 & 191.02 & & & 90 & 179.48 & & & 90 & 184.96 & & \\
\hline Inter & 65 & 184.73 & & & 65 & 185.33 & & & 65 & 183.86 & & \\
\hline B. A & 70 & 202.46 & & & 69 & 221.17 & & & 69 & 212.38 & & \\
\hline Higher & 41 & 248.72 & & & 41 & 226.96 & & & 41 & 243.51 & & \\
\hline Husband qual & icatio & & & & & & & & & & & \\
\hline Illiterate & 35 & 152.21 & 18.641 & $0.005^{b^{*}}$ & 35 & 149.03 & 18.981 & $0.004^{\mathrm{b}^{*}}$ & 35 & 147.54 & 23.100 & $0.001^{b^{*}}$ \\
\hline Primary & 26 & 188.81 & & & 26 & 211.94 & & & 26 & 198.10 & & \\
\hline Secondary & 25 & 144.48 & & & 25 & 148.48 & & & 25 & 139.64 & & \\
\hline Matriculation & 128 & 183.01 & & & 128 & 179.91 & & & 128 & 179.53 & & \\
\hline Inter & 62 & 197.10 & & & 62 & 192.27 & & & 62 & 195.18 & & \\
\hline B. A & 62 & 224.20 & & & 62 & 222.56 & & & 62 & 224.99 & & \\
\hline higher & 44 & 221.77 & & & 42 & 219.12 & & & 42 & 227.48 & & \\
\hline Mode of deliv & & & & & & & & & & & & \\
\hline $\mathrm{CS}$ & 176 & 166.54 & 13735.00 & $0.001^{\mathrm{a}^{*}}$ & 175 & 178.43 & 15825.500 & $0.024^{\mathrm{a}^{*}}$ & 175 & 169.75 & 14305.500 & $0.001^{\mathrm{a}^{*}}$ \\
\hline NVD & 206 & 212.83 & & & 205 & 200.80 & & & 205 & 208.22 & & \\
\hline
\end{tabular}

Mann-Whitney test $(\mathrm{p} \geq 0.05)^{\mathrm{a}}$, Kruskal-Wallis test $(\mathrm{p} \geq 0.05)^{\mathrm{b}},{ }^{*} \mathrm{P}$-value $>0.05$ is considered statistically significant 


\section{DISCUSSION}

Poor postpartum quality of life has a devastating effect on the health of mothers, infants and their families. Postpartum depression, mode of delivery and socio-demographic factors tend to reduce postpartum quality of life of mothers. The results of the present study highlighted that women undergoing normal vaginal delivery had overall better health related quality of life as compared to women who had cesarean sections. Postpartum period is physically and mentally challenging period for the new mothers. Physical functioning in postpartum is important to retain physical and mental health of mother and her newborn. The results of the present study reported that physical functioning in postpartum women after normal vaginal delivery was better health domain as compared to cesarean section. Role emotional and role physical in women undergone normal vaginal delivery was not that much limited in terms of cut down on the amount of time spent, accomplished less than expected and kind of work; however, role physical like difficulty performing the work or other activities was mostly limited. Most of these postpartum women were enjoying good general health in almost all health domains. This might be due to surgical intervention involved in cesarean section which leads to slow recovery of women in the postpartum period and eventually poor physical health. These findings are in line with other studies conducted in Iran and Netherland where women after NVD had highest mean scores in physical HRQOL domains as compared to cesarean section [8-10]. Bodily pain can adversely affect the health of women in the postpartum period. The results of the present study revealed that bodily pain was worst health domain irrespective of mode of delivery. However, bodily pain domain was seen much adversely affected in women with cesarean sections as compared to normal delivery. This might be due to chronic pains associated with cesarean section. The results of present study are in line with studies conducted in Iran and Canada, which reported bodily pain was more associated with cesarean sections [11, 12]. Age has a significant linkage with postpartum quality of life of mothers. The results of present study showed that women in age group between 21-25 had overall better HRQOL in all domains of physical and mental health while women in age group between 31-35 had worst mean scores. These results are consistent with study conducted in Iran where women aged less than 30 had higher mean scores in all domains of health related quality of life as compared to women aged greater than 30, with significant difference in domains of bodily pain, vitality and social functioning [13]. Time since delivery of a baby can be a significant predictor of postpartum quality of life. The results of the present study highlighted that as time passes women's postpartum quality of life was improved. These results are incongruent with studies conducted in Iran where health related quality of life was improved from first time period to second time period $[14,15]$. Gender of infant can be linked to postpartum quality of life in societies where there is preference for a specific gender. The results of the present study also revealed that women with female newborn infants had worst mean scores on all domains of HRQOL as compared to mothers who delivered male infants, but there was no significant difference in their health related quality of life. This might be due to social pressure faced by mothers and gender biasness in our society. In contrast to present finding, a study conducted in China reported poor postpartum quality of life in mothers with male infants, uneducated husbands and less postnatal home visits [16]. Postpartum women delivering their babies in private hospitals had better HRQOL as compared to mothers delivering in public hospitals and reason behind this might be better health services provided in private sector. In current study, working women had better HRQOL than housewives in all domains, except social functioning and this might be due to better awareness regarding health among working women. Current study findings are in agreement with a study conducted in Taiwan, in which employed women had better general health than unemployed women [17]. Beside this, the results of present study showed women living in combined family systems had better HRQOL scores in all domains as compared to women living in separate family systems, which can be due to higher level of support provided to women living in combined families. Moreover, women with higher education had better
HRQOL. Similar situation was reported in a study conducted in Iran, where women with college degree had higher HRQOL [13].

\section{CONCLUSION}

The results of the present study concluded that postpartum quality of life of most of the women undergoing normal vaginal delivery was good as compared to women undergoing cesarean sections in twin cities of Pakistan. Surgical intervention during cesarean might lead to consistent postpartum pain, inability to cope with needs of newborn and family which in turn had reduced postpartum quality of life among women. Therefore, they should be guided about the pros and cons of modes of delivery and must be involved in decision making. Consequently, normal vaginal delivery should be considered as first choice in absence of any medical complication and cesarean sections must only be restricted to instances medically justified in order to improve postpartum health related quality of life among women.

\section{LIMITATION}

The study was conducted in the two cities of Pakistan and the results of the study may not be generalizable to other parts of the country. Unavailability of an updated database of post partum women in twin cities was also a major hurdle in data collection.

\section{ACKNOWLEDGEMENT}

We thank the MS of private and public hospitals for their support to study. The authors have no financial interests.

\section{AUTHORS CONTRIBUTIONS}

M. Mconcieved the idea of research, conducted statistical analysis and manuscript writing. Z. A and A. H conducted literature review and data collection. A. $\mathrm{H}$ helped in statistical analysis and manuscript editing.

\section{CONFLICT OF INTERESTS}

The authors declare no conflict of interest

\section{REFERENCES}

1. Abbas MS, Mortazavi F, Chaman R, Khosravi. Quality of life after cesarean and vaginal delivery. Oman Med J 2013;28:245-51.

2. Shabab U, Tahir S. Effect of obesity on cesarean section rate. Int J Sur Pak 2010;15:92.

3. Sahbanathul MP, Pavithra G, Pavithran G, Priyanka K, Sandhiya R. Assess the knowledge and practice of reproductive aged tribal women on family welfare methods. Int J Pharm Pharm Sci 2016;9:121-4.

4. Mohamed HAS. Prevalance of postnatal depression and associated risk factors among South Asian mothers living in a newly developing country. Asian J Pharm Clin Res 2016; 9:57-61.

5. Khawaja N, Yousaf T, Tayyeb R. Analysis of caesarean delivery at a tertiary care hospital in Pakistan. J Obstet Gynaecol 2004;24:139-41.

6. Sowmya D, Kumar DCP. Comparison of high sensitive c-reactive protein levels in neonates delivered by different modes of delivery. Asian J Pharm Clin Res 2014;7:6-8.

7. National Bioethics Committee Pakistan. Introduction; 2017. Available from: http://nbcpakistan.org.pk/. [Last accesseed on 10 Oct 2016].

8. Sadat Z, Taebi M, Saberi F, Abedzadeh KM. The relationship between mode of delivery and postpartum physical and mental health related quality of life. Iran J Nurs Midwifery Res 2013;18:499-504.

9. Zahra Kavosi AK, Fatemeh S, Maryam K, Mohammad K, Marzieh E. A comparison of mothers' quality of life after normal vaginal, cesarean, and water birth deliveries. Int J Community Based Nurs Midwifery 2015;3:3.

10. Gerard JA, Duvekot JJ, Hop WC, Essink BML, Beckers EA, Karsdorp VH, et al. New insights into fatigue and health-related quality of life after delivery. Acta Obstet Gynecol Scand 2007;86:579-84. 
11. Mcgovern P, Dowd B, Gjerdingen D, Gross CR, Kenney S, Ukestad L, et al. Postpartum health of employed mothers $5 \mathrm{~W}$ after childbirth. Ann Fam Med 2006;4:159-67.

12. Majzoobi MM, Majzoobi MR, Nazari PF, Biglari M. Comparing quality of life in women after vaginal delivery and cesarean section. J Midwifery Reprod Health 2014:2:207-14.

13. Rezaei N, Azadi A, Zargousi R, Sadoughi Z, Tavalaee Z, Rezayati M. Maternal health-related quality of life and its predicting factors in the postpartum period in Iran. Scientifica 2016. http://dx.doi.org/10.1155/2016/8542147.

14. Torkan B, Parsay S, Lamieian M, Kazemnezhad A, Montazeri A. Comparative analysis of life quality in mothers after cesarean section and normal vaginal delivery. Iran J Nurs Midwifery Res 2008;12:3.

15. Torkan B, Parsay S, Lamyian M, Kazemnejad A, Montazeri A Postnatal quality of life in women after normal vaginal delivery and caesarean section. BMC Pregnancy Childbirth 2009;9:4.

16. Huang K, Tao F, Liu L, Wu X. Does delivery mode affect women's postpartum quality of life in rural China? J Clin Nurs 2012;21:1534-43.

17. Wang P, Liou SR, Cheng CY. Prediction of maternal quality of life on preterm birth and low birthweight: a longitudinal study. BMC Pregnancy Childbirth 2013;13:1. 